\title{
Direct visual access in reading for meaning
}

\author{
DAVID W. GREEN \\ University College London, London WCIE 6BT, England \\ and \\ TIM SHALLICE \\ National Hospital, London WCIN SBG, England
}

\begin{abstract}
Two experiments examined whether phonological recoding is an obligatory stage in reading for meaning or whether direct access to a word's semantic representation is the general rule. The first study demonstrated that the time to make a semantic decision about a pair of words was much more delayed by misspelling than was the time to make a phonological one. The second study investigated the effect of varying the syllabic length of a word on reaction time in a category decision task. While reaction time varied with the semantic difficulty of the category decision, it generally proved invariant with respect to syllabic length. It is argued that reading for meaning generally uses a direct route from visual form to semantic representation.
\end{abstract}

There has been much discussion in recent years on the conditions under which reading for meaning depends upon phonological recoding (see Bradshaw, 1975). A number of workers have claimed that phonological recoding is the standard way of reading (Rubenstein, Lewis, \& Rubenstein, 1971; Rubenstein, Richter, \& Kay, 1975) or, at least, that it is widely used (Meyer, Schvaneveldt, \& Ruddy, 1974).

One of the strongest arguments against these views is the difficulty of reading words which have been misspelled in such a way that their correct pronunciation is unambiguously preserved (Bower, 1970). However, Meyer et al. (1974) argued that the slowness in reading such words could arise prior to phonological recoding due to difficulties either in "visual preprocessing" or in the transformation of visual information into phonological form. An experiment by Baron (1973) avoided both of these difficulties. He used words (e.g., "not") in a context that was only meaningful for their homophones (e.g., "knot"), as in "tie the not." If phonological recoding is obligatory, it should be more difficult to decide that such phrases are "nonsense." Subjects were in fact no slower in dealing with such phrases than with control nonhomophonic phrases. However, they did make a significantly greater number of errors, so the results are inconclusive.

\section{EXPERIMENT 1}

We attempted to make a direct test of the two Meyer et al. hypotheses. If either is true, then, given that phonological recoding is the standard way by which

We would like to thank Vanessa Moore for her assistance in conducting the experiments, and the Psychology Department, University College London, for providing facilities and assistance. words are read, all tasks which involve such recoding should be equally slowed by the use of misspelled words. In Experiment 1 we compared the use of misspelled words in a semantic task, which requires reading for meaning, with their use in a rhyming task.

\section{Method}

Subjects. The subjects were 32 first-year undergraduate students from the Psychology Department, University College London. They were unpaid volunteers, tested individually.

Design. Subjects were assigned upon appearance in the laboratory to one of the four independent groups which represented the four combinations of the two variables of task (rhyming vs. semantic) and spelling pairs (correctly spelled vs. incorrectly spelled). There were eight subjects in each group.

The experimental trials were divided into two randomized sets of 20 , balancing within each for the number of "same" and "different" pairs. The design controlled the order of presentation of the sets within each group. Half the subjects responded "same" with their dominant hand and half with their nondominant hand.

Materials. The experimental materials consisted of 20 pairs of monosyllabic words that rhymed (e.g., dote, stoat; urge, verge) and 20 pairs that did not (e.g., poise, wise; dial, foal). The former were the "same" pairs for subjects in the rhyming task and the latter, the "different" pairs. The words were selected so that the rhyming and nonrhyming pairs could not be distinguished in terms of the visual similarity of their words. As an index of similarity, we computed the average number of letters the pairs had in common (ignoring the initial consonant cluster). For correctly spelled word pairs, the rhyming instances had 2.0 letters in common and the nonrhyming instances 2.3 . For misspelled word pairs (see below), the rhyming examples had 2.0 letters in common and the nonrhyming examples 2.2 . (Taking into account the position of identical letters in the word did not materially alter the relative visual similarity indices.)

The words were divisible into two broad semantic categories that referred either to animate entities or aspects of them (e.g. foe, crow; poise, wise), or to inanimate entities or aspects of them (e.g., squall, shawl; dawn, rain). Half the words referred to animate entities and half to inanimate entities. When the two words in a pair were drawn from the same broad category, they were "same" pairs for the semantic task; when from different 
broad categories, they were "different" pairs. Half of the rhyming pairs and half of the nonrhyming pairs were "same" trials for the semantic task.

In order to create the misspelled pairs, generally one and not more than two letters in each word were either changed or rearranged. The exact method used for each word pair depended on which left the pairs equally similar visually and allowed them to be pronounced in the same way. For example, the pair (dote, stoat) became (doat, stote); the pair (urge,verge) became (erge, vurge); (poise, wise) and (dial, foal) became (poize, wize) and (dile, fole).

Procedure. The stimulus pairs were typed in lowercase, one above the other, on standard tachistoscope cards, and presented in an Electronics Developments automatic three-field tachistoscope. The subjects were instructed that the experiment concerned the way we read words and retrieve information about them. For the rhyming task subjects were told to respond "same" if the two words on the stimulus cards rhymed and "different" if they did not rhyme, by pressing the appropriate microswitch. For the semantic task subjects were instructed to respond "same" (1) if both words referred to animate entities or their aspects or (2) if both words referred to inanimate entities or their aspects. Otherwise, they were to respond "different." Each subject was told that all the words in the experiment were English words and that they were to respond as quickly and as accurately as possible. After a practice series of eight trials, consisting only of correctly spelled pairs, during which subjects were given feedback, the subjects in the misspelling conditions were told that subsequent word pairs would be incorrectly spelled, but that they should perform the task as before. In all conditions four further practice trials, with feedback, were given.

Each trial consisted of a "ready" signal, followed by the replacement of the fixation field by the stimulus field and the triggering of a standard $10-\mathrm{msec}$ response timer. A subject responded by pressing either the microswitch marked "same" or the one marked "different."

Subjects were questioned about their performance after the experiment.

\section{Results and Discussion}

The dependent variable was the time taken to make a correct "same" or "different" response. Errors were much higher on the semantic than on the rhyming task (averaging 21\% and 5\%, respectively), but misspelling had no apparent effect in either case. Table 1 displays average correct latency as a function of both Task and Spelling.

As can be seen, latency is a function of both Task and Spelling. Reaction time in the semantic task was significantly greater than in the rhyming task $\left[\mathrm{min} \mathrm{F}^{\prime}(1,34)=\right.$ $40.13, \mathrm{p}<.001]$. Misspelled word pairs took longer than correctly spelled pairs $\left[\min \mathrm{F}^{\prime}(1,33)=8.8, \mathrm{p}<.01\right]$. As can be seen from the significant Task by Spelling interaction, this effect was principally confined to latencies

Table 1

Latency in Seconds as a Function of Task and Spelling

\begin{tabular}{|c|c|c|c|c|}
\hline \multirow[b]{3}{*}{ Task } & \multicolumn{4}{|c|}{ Spelling } \\
\hline & \multicolumn{2}{|c|}{ Correct } & \multicolumn{2}{|c|}{ Incorrect } \\
\hline & RT & $\mathrm{SE}$ & RT & SE \\
\hline Rhyming & 1.50 & .12 & 1.67 & .11 \\
\hline Semantic & 2.68 & .16 & 4.24 & .30 \\
\hline
\end{tabular}

in the semantic task $\left[\min \mathrm{F}^{\prime}(1,32)=5.63, \mathrm{p}<.025\right]$. No other effects were significant on the combined analysis.

There is some support for the claim that phonological recoding occurs more slowly for misspelled words, since there is an effect of spelling in the rhyming task. This effect was significant analyzing by word pairs $(z=2.37$, $\mathrm{p}<.01$, sign test, two-tailed), but not by subjects $(\mathrm{t}<1)$. However, this result is also compatible with the idea that the phonological form of a word is accessed after its semantic representation has been located.

The main result is that misspelling affects a semantic task much more adversely than a rhyming task. For the semantic task the difference is $1,560 \mathrm{msec}$, while for the rhyming task it is only $170 \mathrm{msec}$. For virtually all word pairs (39 out of 40), the difference is greater on the semantic task than on the rhyming task. It could be argued that the slight delay involved in recoding misspelled words phonologically could induce an extra memory load, or extra confusion, for the more difficult semantic task. If this were the case, one would expect that the slowing produced by misspelling would increase with the difficulty of the semantic task. However, for the semantic task, there is a nonsignificant negative correlation between the reaction times for correctly spelled word pairs and the slowing produced by misspelling them. Hence, it appears that few, if any, words in this experiment are read by the use of the phonological route alone.

If the direct route is normally the one used in the reading of correctly spelled words, how is it possible to account for the large effect of misspelling in the semantic task? Assuming that meaning can be accessed about as rapidly from a word's visual representation as from its phonological representation, then a simple effect of misspelling would be to add the time needed to convert the misspelled visual form into the appropriate phonological representation. The rhyming task using misspelled words provides an upper bound for this process. Yet the time needed to complete this process would not fully account for the misspelling effect. The extra memory load mentioned above may also be relevant. However, the confusion that would arise from accessing the meaning corresponding to visually similar graphemes could well be a more important factor.

\section{EXPERIMENT 2}

The results of the previous experiment are incompatible with the strong version of phonological recoding theory, that it is the sole process in reading for meaning. They are consistent with the findings that at least some words can be read by patients lacking the phonological route, either due to innate deafness (Gibson, Shurcliffe, \& Jonas, 1970) or to an acquired neurological lesion (Marshall \& Newcombe, 1973; Shallice \& Warrington, 1975). However, the results are compatible with the weak version of phonological recoding theory, which 
assumes that both phonological recoding and direct accessing are involved in reading. For instance, the results would fit with the theory that semantic representations are elicited by phonological recoding but then must be checked directly against the visual input, as in the Becker, Schvaneveldt, and Gomez (Note 1) theory.

Evidence for the phonological recoding of individual words arises from three sources. First, there is the difficulty of deciding that pronounceable nonwords that sound like words are not words (Rubenstein et al., 1971; Coltheart, Davelaar, Jonasson, \& Besner, 1976). Second, Meyer et al. (1974) found that words that do not rhyme with a previously presented, visually similar word (e.g., "couch," "touch") take longer to classify as words. Third, Marshall and Newcombe (1973) have shown that certain patients with acquired dyslexia, "surface dyslexics," make errors such as reading "just" for "guest" and "off" for "of." These errors can be explained by assuming that only the phonological route is available to these patients, and grapheme-phoneme conversion rules are being misapplied (e.g., a soft "g" is read instead of a hard "g"). All three of these lines of work are compatible with the phonological route operating on grapheme components. (A grapheme component would be the graphemic representation of a phoneme, e.g., " $t$ " or "ch," or of certain morphemes, e.g., "tion," "ing," "ed.") Two of these lines of work are in fact incompatible with the route operating on the word-form as a whole. For example, in the Meyer et al. (1974) experiment, the difficulty in deciding that "touch" is a word implies that it is internally sounded incorrectly to rhyme with "couch."

If, then, the phonological route operates on grapheme components, a multisyllabic word would require more components to be transmitted than would a monosyllabic word. Therefore, unless one makes a number of rather implausible assumptions about the process of constructing the phonological representation, it should take longer to construct that representation for a multisyllabic word than for a monosyllabic word. It would, for instance, be necessary to assume that grapheme components were extracted and transmitted in equal time and in an unlimited parallel fashion.

In consequence, even on the weak version of the phonological recoding theory, multisyllabic words would be expected to take longer to recognize than monosyllabic words. In conflict with this prediction, Klapp, Anderson, and Berrian (1973) found no effect of the number of syllables on speed of recognition in reading for meaning. However, their experiment involved multiple presentation of a very small number of words, and no control was made of the ease of the semantic decision. Their null effect might, therefore, have stemmed from the particular character of the words used or from subjects' learning the stimulus set and the appropriate responses to it. Experiment 2 involved a related type of procedure that maximized the difference in syllabic length between words whose semantic difficulty was controlled. The effect of syllabic length was investigated in a category decision task.

\section{Method}

Subjects. The subjects were 16 undergraduate students from the Psychology Department, University College London. They were unpaid volunteers, tested individually.

Design. In the category decision task, subjects reacted to eight kinds of trials created by combining the variables of truth (true vs. false), syllabic length (short vs. long) and production frequency in a category (high vs. low). The trials were ordered according to an 8 by 8 Williams square and the relevant examples grouped into two blocks of 40 trials. The design counterbalanced order of presentation across subjects. Half the subjects responded true with their dominant hand and half responded with their nondominant hand.

Materials and procedure. The words chosen as category instances in the study were selected from 40 categories of the Battig-Montague (1969) category norms. For each category, two words were selected that were comparable in production frequency and Thorndike-Lorge (1944) frequency but different in length. Half of the words were high in production frequency (category averages ranging from 30 to 250 ) and half were low (category averages ranging from 4 to 30 ). The short words were one or two syllables in length (ranging from 3 to 6 letters), whereas the long words were three or four syllables in length (ranging from 6 to 12 letters). Examples of high production frequency pairs are "clove, cinnamon" for the category "flavoring" and "wasp, grasshopper" for the category "insect." Examples of low production frequency pairs are "squash, gymnastics" for the category "sport" and "clerk, secretary" for the category "occupation." Half of the categories with words high in production frequency were assigned to the "true" condition and half to the "false" condition. The low production frequency categories were treated in the same way. In the "true" condition, each of the instances of a category was preceded by the appropriate category name. In the "false" condition, the two instances were preceded on their respective trials by one of the category names of the "true" condition. Hence, over trials, four instance-category decisions were made with respect to a particular category name. Twenty trials intervened between each category name repetition.

Subjects were told that the experiment concerned the way people understand the meanings of words, and that they were to decide as quickly and as accurately as possible whether the instance word was a member of the previously presented category by pressing either the microswitch marked "true" or the one marked "false." Each trial commenced with a "ready" signal, followed by the presentation of the category name and, $2 \mathrm{sec}$ later, by the instance word. Subjects were given a practice series of eight trials before two series of 40 trials in the experimental session itself. In view of the possible effects of subvocalizing on reading, subjects were questioned after the experiment about the way they had performed the task.

\section{Results and Discussion}

The basic dependent variable was the time to decide whether an instance was a member of a prespecified category. As in the previous experiment, the data were analyzed by subjects and by words. "True" results were analyzed separately from "false" because of the likelihood of different decision processes (e.g., Anderson \& Reder, 1974). Error latencies were excluded from the analyses and averaged $2 \%$. It was clear from subjects' 
introspections that some subjects vocalized and others did not. Fortuitously, half the subjects reported vocalizing. Moreover, factoring out this variable maintained the balance of the design. Since it seemed plausible that strategy difference might exert a profound influence on the latencies, this variable was factored out.

Two types of analysis were performed on the results. In both cases, median reaction times were used to deal with the problem of the very small number of very long responses. Other methods which have been used appear arbitrary. The use of medians has the consequence that the $\min F^{\prime}$ values quoted are only an approximation to true min $F^{\prime}$. However, since the main argument depends upon nonrejection of the null hypothesis, min $\mathrm{F}^{\prime}$ estimates are not directly relevant to it, and their accuracy is less important than reducing the chance of a Type II error. As the initial analyses (reported below) produced a relation between mean and standard error over conditions, a second set of analyses was performed using appropriate logarithmic transformations. However, there was no substantive change in the results of the analyses.

Average median reaction times for "true" responses as a function of the production frequency of a word in its category and its syllabic length are displayed in Table 2.

For the "true" results, there was a significant effect of production frequency $\left[\min \mathrm{F}^{\prime}(1,29)=4.24, \mathrm{p}<.05\right]$, which confirms the finding of Rosch (1975). However, there was no effect of word length on either subject or word analysis ( $F<1$ in both cases). Vocalizers tended to react more slowly than nonvocalizers, but this finding did not attain significance on a combined analysis $\left[\min F^{\prime}(1,29)=2.82\right]$. In fact, the tendency is largely attributable to two vocalizers who reacted more than $1 / 2 \mathrm{sec}$ slower than any other subject. Neither analysis revealed any significant interactions. The lack of interactions with vocalizing suggests that vocalization followed semantic access in this condition; perhaps vocalizers are people who normally fail to inhibit the execution of the phonological code.

The "false" results are shown in Table 3. They show no overall effect of syllabic length $(F<1$ for both subject and word analyses). However, there is a sug-

Table 2

Latency in Milliseconds for True Trials as a Function of a Word's Production Frequency, Syllabic Length, and Subject's Reading Strategy

\begin{tabular}{|c|c|c|c|c|c|}
\hline \multirow[b]{3}{*}{ Strategy } & \multirow[b]{3}{*}{ Length } & \multicolumn{4}{|c|}{ Production Frequency } \\
\hline & & \multicolumn{2}{|c|}{ High } & \multicolumn{2}{|c|}{ Low } \\
\hline & & $\mathrm{RT}$ & SE & RT & SE \\
\hline Nonvocalizing & $\begin{array}{l}\text { Short } \\
\text { Long }\end{array}$ & $\begin{array}{l}664 \\
677\end{array}$ & $\begin{array}{l}64 \\
56\end{array}$ & $\begin{array}{l}717 \\
723\end{array}$ & $\begin{array}{l}67 \\
69\end{array}$ \\
\hline Vocalizing & $\begin{array}{l}\text { Short } \\
\text { Long }\end{array}$ & $\begin{array}{l}948 \\
947\end{array}$ & $\begin{array}{l}168 \\
149\end{array}$ & $\begin{array}{l}1085 \\
1091\end{array}$ & $\begin{array}{l}199 \\
193\end{array}$ \\
\hline
\end{tabular}

Table 3

Latency in Milliseconds for False Trials as a Function of a Word's Production Frequency, Syllabic Length, and Subject's Reading Strategy

\begin{tabular}{|c|c|c|c|c|c|}
\hline \multirow[b]{3}{*}{ Strategy } & \multirow[b]{3}{*}{ Length } & \multicolumn{4}{|c|}{ Production Frequency* } \\
\hline & & \multicolumn{2}{|c|}{ High } & \multicolumn{2}{|c|}{ Low } \\
\hline & & RT & SE & RT & SE \\
\hline Nonvocalizing & $\begin{array}{l}\text { Short } \\
\text { Long }\end{array}$ & $\begin{array}{l}686 \\
763\end{array}$ & $\begin{array}{l}53 \\
92\end{array}$ & $\begin{array}{l}724 \\
761\end{array}$ & $\begin{array}{l}65 \\
81\end{array}$ \\
\hline Vocalizing & $\begin{array}{l}\text { Short } \\
\text { Long }\end{array}$ & $\begin{array}{r}1027 \\
990 \\
\end{array}$ & $\begin{array}{l}163 \\
161 \\
\end{array}$ & $\begin{array}{r}1029 \\
958 \\
\end{array}$ & $\begin{array}{l}159 \\
159\end{array}$ \\
\hline
\end{tabular}

*With respect to its correct category

gestion of an interaction between the subject's strategy and syllabic length. On the subject analysis alone, the difference between vocalizers and nonvocalizers was greater for short words than for long words $[F(1,14)=$ $6.95, \mathrm{p}<.025]$. The exact reasons for this interaction are unclear, especially as it is in the opposite direction from that predictable from the properties of the phonological route. One semantic possibility is that unprimed short words have less sharply defined singleness of meaning; they seem more like homographs. If they do possess this property, then subjects who have less confidence over the decision process (the vocalizers) should find it more difficult to reject short words than long words. This potential interaction does, however, make the interpretation of the data more complex with respect to the main hypothesis.

The crucial result is the absence of any effect of syllabic length in the "true" condition. There is no evidence whatsoever supporting the view that the phonological route is used in this condition. Also, since on average the number of letters in a word increases with the number of syllables, the failure to find an effect of word length is in conflict with any theory of visual word recognition which involves a stage of serial or semiserial processing over letters or over other word components. In this respect, the results are compatible with the findings that word length has no effect on tachistoscopic span (Allport, Note 2) or on recognition thresholds (Richards, Note 3).

\section{GENERAL DISCUSSION}

The present findings support the notion that meaning is accessed directly from visual form and does not normally involve prelexical phonological recoding. In the first experiment, enforcing phonological recoding by using misspelling delayed semantic judgments by far more than the slowing in the operation of that route itself, as assessed by the effect of misspelling on the rhyming task. The logic of the second experiment is more complex. Published evidence supports the view that the phonological route operates on word components rather than on whole word forms. Unless 
one makes implausible assumptions about how this information is transformed from graphemic to phonological form the speed of operation of the phonological route should vary with the amount of information to be transmitted. There is no evidence for any such effect in Experiment 2, which supports the view that the phonological route is not being used. The case need not, however, rest solely on the plausibility of the assumptions. In theory, they could be tested by conducting the same type of experiment using nonwords that are homophonic with words. In this case, an effect of syllabic length would be expected, as the phonological route could not then be bypassed.

That the direct route is the only route used in reading is not the only view compatible with the obtained results. Both routes could be used on those occasions in which the word to be read lacks an appropriate semantic context, as considered, for example, by Becker, Schvaneveldt, and Gomez (Note 1). From the first experiment it is clear that the reading of such words must involve some direct visual information. The findings in the second experiment which are also relevant to this view-the "false" results-are made difficult to interpret by the potential interaction between strategy and length.

Most of the results that suggest an important role for phonological recoding have used the lexical decision task. Yet, on this task, Frederiksen and Kroll (Note 4) have shown that positive (i.e., word) reaction times are affected neither by word length nor by syllabic structure. Moreover, detailed analysis shows that evidence of substantial phonological recoding in the reading of words (as opposed to nonwords) is hard to come by in lexical decision tasks (Coltheart et al., 1976). The major exception appears to be the results of Meyer et al. (1974), where graphemically similar, but phonemically different, word pairs are responded to more slowly than are control pairs. On the assumption that rhyming increases the speed of the operation of the phonological route, even these results could be accounted for by the race model of Coltheart et al. (1976), in which both routes operate in parallel but the phonological route normally operates more slowly than the direct route; a stimulus which is graphemically similar to a previous stimulus would have rhyming phonological representation constructed more quickly than would a control word. This incorrect phonological representation could then interfere with the operation of the direct route. In any case, the lexical decision task would seem, a priori, much less likely to provide a useful model for normal reading for meaning than the semantic decision task.

The principal experimenter who has used the semantic decision task to attack this problem is Kleiman (1975). Using a logic analogous to our first experiment, he found that a concurrent shadowing task slowed rhyming decisions much more than semantic decisions. Kleiman's findings are subject to the alternative explanation that rhyming decisions depend upon storage of the phonological representation of the first word, and it is this storage system (primary memory) that is affected by concurrent shadowing. However, the plausibility of attributing his result to this potential artifact is much weakened by the correspondence between his result and ours. Taking into account the lexical decision task results as well, the argument presented both by Kleiman and by Coltheart et al. (1976), that phonological effects in reading occur primarily after lexical access rather than before, seems much the most plausible position.

\section{REFERENCE NOTES}

1. Becker, C. A., Schvaneveldt, R., \& Gomez, L. M. Semantic, graphemic and phonetic factors in word recognition. Paper presented to the Psychonomic Society, St. Louis, 1973.

2. Allport, D. A. Word recognition and the recognition buffer. Paper presented to the Experimental Psychology Society, London, 1973.

3. Richards, L. G. Processes in word recognition. Paper presented to the Psychonomic Society, Denver, 1975.

4. Frederiksen, J. R., \& Kroll, J. F. Phonemic recoding and lexical search in the perception of letter arrays. Paper presented to the Psychonomic Society, Boston, 1974.

\section{REFERENCES}

Anderson, J. R., \& Reder, I. M. Negative judgements in and about semantic memory. Journal of Verbal Learning and Verbal Behavior, 1974, 13, 664-681.

Baron, J. Phonemic stage not necessary for reading. Quarterly Journal of Experimental Psychology, 1973, 25, 241-246.

Battig, W. F., \& Montague, W. E. Category norms for verbal items in 56 categories: A replication and extension of the Connecticut category norms. Joumal of Experimental Psychology Monograph, 1969, 80(No. 3 Part 2).

Bow ER, T. G. R. Reading by eye. In H. Levin \& J. Williams (Eds.), Basic studies in reading. New York: Basic Books, 1970.

Bradshaw, J. L. Three interrelated problems in reading: A teview. Memory \& Cognition, 1975, 3, 123-134.

Coltheart, M., Davelaar, E., Jonasson, J. T., \& Besner, D. Access to the internal lexicon. Attention and performance, 1976. 6. in press.

Gibson, E. J., Shurcliffe, A., \& Jonas, A. Utilization of spelling patterns by deaf and hearing subjects. In $H$. Levin \& J. P. Williams (Eds.), Basic studies in reading. New York: Basic Books, 1970.

Klapp, S. T., Anderson, W. G., \& Berrian, R. W. Implicit speech in reading reconsidered. Journal of Experimental Psychology, 1973, 100, 368-374.

KLEIMAN, G. M. Speech recoding in reading. Journal of Verbal Learning and Verbal Behavior, 1975, 14, 323-339.

Marshall, J. C., \& Newcombe, F. Patterns of paralexia: A psycholinguistic approach. Journal of Psycholinguistic Research, 1973, 2, 175-199.

Meyer, D. E., Schvaneveldt, R. W., \& Ruddy, M. G. Functions of the graphemic and phonemic codes in visual word recognition. Memory \& Cognition, 1974, 2, 309-323.

Rosch, E. Cognitive representation of semantic categories. Journal of Experimental Psychology, 1975, 104, 192-233.

Rubenstein, H., Lewis, S. S., \& Rubenstein, M. A. Evidence for phonemic recoding in word recognition. 
Journal of Verbal Learning and Verbal Behavior, 1971, 10, 645-657.

Rubenstein, H., Richter, M. L., \& Kay, E. J. Pronounceability and the visual recognition of nonsense words. Journal of Verbal Learning and Verbal Behavior, 1975, 14, 651-657.

Shallice, T., \& Warrington, E. K. Word recognition in a phonemic dyslexic patient. Quarterly Journal of Experimental Psychology, 1975, 27, 187-199.
THORNDIKE, E. L., \& LoRge, I. The teacher's wordbook of 30,000 words. New York: Teachers College, Columbia University, Bureau of Publications, 1944.

(Received for publication March 9, 1976; revision received June 9,1976 .) 